\title{
Stage IA Cervical Cancer AJCC v8
}

National Cancer Institute

\section{Source}

National Cancer Institute. Stage IA Cervical Cancer A/CC v8. NCI Thesaurus. Code C139735.

Stage IA includes: T1a, Any N, M0. T1a: Tumor diagnosed only by microscopy. Stromal invasion with a maximum depth of $5.0 \mathrm{~mm}$ measured from the base of the epithelium and a horizontal spread of $7.0 \mathrm{~mm}$ or less. Vascular space involvement, venous or lymphatic, does not affect classification. M0: No distant metastasis. (AJCC 8th Ed.) 